\title{
Static loading test on the aluminum honeycomb mat
}

\author{
Shaohui Zhou ${ }^{1, a^{*}}$,Liangcai Cai ${ }^{2, b}$ \\ ${ }^{1}$ Department of Airport and Architecture Engineering, Air force Engineering University,Xi'an,China \\ ${ }^{2}$ Department of Airport and Architecture Engineering, Air force Engineering University,Xi'an,China \\ azshui617@126.com, 'biangcai007@126.com
}

Keywords: austere airfield; aluminum honeycomb; mat; static load test; interlocking action; voids Abstract. In order to research the feasibility of aluminum honeycomb mat to sustain $\mathrm{S}$ aircraft over austere airfield pavement, static loading test was applied in field experiment. Three test sections were constructed with different strength. The instrument results (displacement and strain) of testing were used to evaluate the performance of mats. The influences of mat thicknesses, soil foundation, locks, interlocking action and voids were analyzed. Experimental results indicate that it is feasible that aluminum honeycomb mat sustain $\mathrm{S}$ aircraft over austere airfield pavement which needs only a Middle-strength soil foundation. Modifications to the panels, locks and joints design are recommended to improve the performance of mats.

\section{Introduction}

Matting systems are one of best remedies when expediency, needs for heavy specialty equipment, and short-term usage situations are considered for military airfields[1-3]. The austere airfields built with stabilized soil or lime-ash soil are usually substandard because of structural capacity and surfacing. A matting system can not only make up for the deficiencies that the original base course is not even enough, but also properly increase the pavement intensity. Currently, demand for rapid deployment of austere airfields highlights the disadvantages of traditional pavement materials used for constructing austere airfields, that airfield construction spends long time. However, advantages of the matting system such as inerratic dimension, convenient transportation and rapid assembly can decrease construction timeline.

AM-2 or AM-X are smaller in mass and greater in intensity, and are used many years for American army. However, they can't meet the requirements of other military new aircraft whose mass and tire pressure become greater. Even the newest composite material is used only for rush repair on part of the airfield crater, because of its cost and capacity. Therefore, it is important to look for a new pavement material. Based on the well performance of AM-2, aluminum honeycomb mat (another aluminum mat) is designed to sustain S aircraft over austere airfield pavement by Center of Airport and Pavement Technology Experiment. Based on the well behavior of aluminum honeycomb composite material in other industry, Aluminum honeycomb mat with small mass, high compressive strength, high strength-weight ratio and steady capacity is considered to fulfill requirements of new heavy weight aircraft properly. However, due to its special structure, great differences will be displayed when the mat is applied for the construction of austere airfields.

\section{Research objective}

The objective of this study is to determine the feasibility of aluminum honeycomb mat to sustain $\mathrm{S}$ aircraft over austere airfield pavement and to select mats with proper dimension and corresponding soil condition before full-scale test in order to save cost and time. The factors influencing the mat's bearing capacity are also analyzed through static tests, which can give suggestion to mats' design for future heavier aircraft. 


\section{Materials}

Experimental mats are provided by private company in Qingdao. Contactor uses commercial off-the-shelf sandwich aluminum honeycomb panel as their prototype mats. The panels are born out of the necessity of large industries that use them, such as road engineering and large equipment rigging and moving groups. Because these panels are not particularly manufactured for an austere airfield application, they are modified for required such application by contactor. Mats' edge is made in concave-convex shape. Due to the transportability key performance parameter (decided by transport pallet), the mat dimensions are limited to no greater than $2400 \mathrm{~mm} \times 1200 \mathrm{~mm}$. Finally, mat is manufactured approximately $2340 \mathrm{~mm}$ long and $1070 \mathrm{~mm}$ wide, if seen as a critical rectangle. The top or bottom mat face sheets are thin aluminum panel with a close aluminum honeycomb core. The core takes the form of hexagon and the honeycomb element is $0.2 \mathrm{~mm}$ thick. The honeycomb hexagon is $6 \mathrm{~mm}$ long. Single honeycomb element and honeycomb core are welded to panels creating a relatively stiff frame for mats. The mats' edge is blocked out and the panel-to-panel connection utilizes cam-lock connector. Because one key performance parameter that the unit mat weight is limited to $80 \mathrm{~kg}$, the mat thickness is also limited. Four kinds of prototype mat are manufactured. All prototype mats are composed of Al 6061-T6. Mat 1 is basic test mat and is tested in all load tests, while mat 2, 3 and 4 are only tested to research that the mat thickness effect on mats' bearing capacity.

The soil is silt clayey. In this test, soil is mainly stabilized with other material to construct different test section for supporting mat loaded by aircraft pressure.

\section{Testing Design}

Three test sections are constructed in experimental fields in Jining, ShanDong province. The test section B is constructed in two layers using stabilized soil as the pavement material. The soil of upper layer (base) is stabilized by con-aid soil stabilizer, with cement and lime used as control stabilizer to accelerate strength improvement. The con-aid soil stabilizer, cement, and lime are used at concentration of $0.015 \%, 4 \%$, and $4 \%$ respectively. The lower layer (subbase) of the stabilized soil pavement is similar to the upper, but cement is used at concentration of 5\%. The cement used during the test is PC 32.5 produced by ZhangShan Cement factory in ShanDong province. Con-aid soil stabilizer is produced by YiTong factory in Beijing. The test section A is constructed only one layer, the same structure with the upper layer of the test section B. While the pavement structure of test section $\mathrm{C}$ is the original compacted soil foundation. All test sections are constructed with a $1 \%$ longitudinal slope and a $1.5 \%$ cross slope for drainage. After three days curing, the integrated resilient modulus of pavement is tested based on Field Test Methods of Subgrade and Pavement for High Engineering[4]. The resilient modulus values of test section $\mathrm{A}, \mathrm{B}$ and $\mathrm{C}$ are $70 \mathrm{MPa}, 110 \mathrm{MPa}$ and $40 \mathrm{MPa}$ respectively. Three test sections present three different soil conditions. Test section A, B and C are corresponding with Middle, High and Low strength soil foundation.

Rigid bearing board method, the same as the test way for integrated resilient modulus of road foundation and surface, is used in the experiment to research the mats' ability. Fig.1 shows the test setup for loading tests.
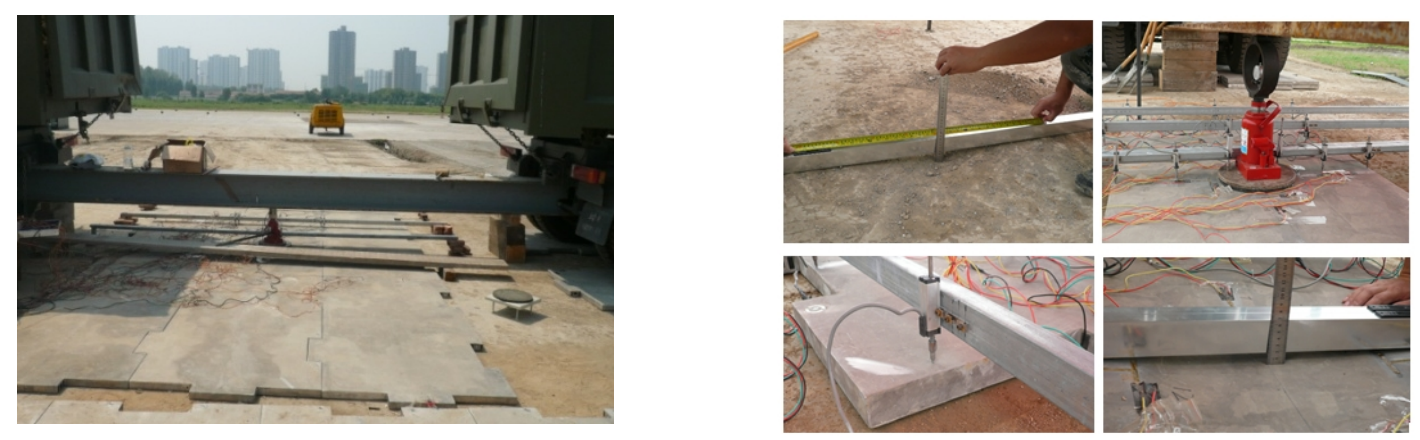

Fig.1 Test setup for loading tests 
In the experiment, four mats with different thickness are tested. Four load locations are investigated : 1) Load in the center of a mat panel (Load location 1);2) Load in the middle point of a mat panel's longitudinal side (Load location 2);3) Load in the middle point of a mat panel's transverse side 1); 4) Load in the corner of a mat panel (Load location 4). Mats are also tested over different soil foundation (include voids) to research the soil condition/voids effect on mats' capacity.

\section{Results and Discussions}

All static tests except mats over Low-strength soil/or soil foundation with voids have the similar phenomenon and trend. Instrumentation readings in the initial stage are small. But as increase of applied load, the displacement increases gradually and the plastic deformation appears in the sandwich mats. In addition, it becomes more difficult to load manually. Then the plastic deformation increases dramatically until the mat becomes totally damaged. However, the amount applied load that plastic deformation appears apparently is not a static value and it is affected by many factors such as mat itself, soil condition, loading location and so on. Therefore, in response to different factors, each of the test results is discussed in details in the following sections. One tire of the main gear of a $\mathrm{S}$ aircraft is loaded to contingency weight $(100 \mathrm{kN})$, with one tire pressure $(1.20 \mathrm{MPa})$. So the displacements and strains when load applied to $10 \mathrm{t}$ are mainly analyzed in the following sections. In addition, based on the requirement demanded by campaign department, the maximum allowable pavement deflection for $\mathrm{S}$ aircraft is limited to $10 \mathrm{~mm}$.

As increase of applied load, more partial failure appears in the mat such as separation between face sheet and honeycomb core, which expands gradually along the direction of separation, and in the end, the mat turns to failure in the position of the partial failure. The failure of matting tests is similar to compression experiment about honeycomb sandwich panel [5-6]which indicates that type defect of honeycomb sandwich structure maybe also affect the function of matting systems installed over soil foundation. Based on contactor's production process, type defect mainly includes separation between face sheet and honeycomb core, honeycomb crack and so on. In addition, during some static tests, bearing board starts to lean as applied load increases. Two points can account for the phenomenon: 1) Part of the soil foundation is not strong enough or roughness is not enough. 2) Defects of honeycomb result in the partial failure and unstableness of the mat.

\section{Mat thickness}

The differences in mat thickness are observed to cause differences in mat displacement over different soil condition with the load placed in the center of mat (Load location 1). Fig.2 illustrates the displacement results of mat testing.

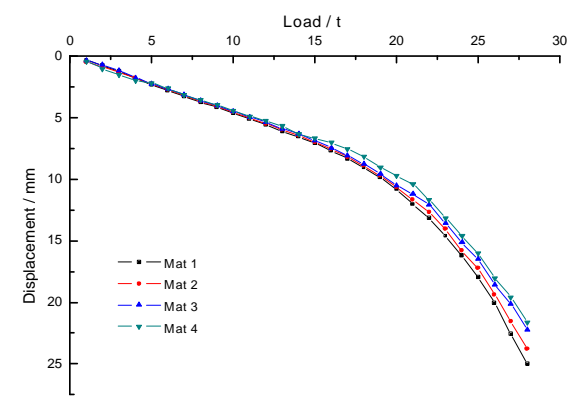

a

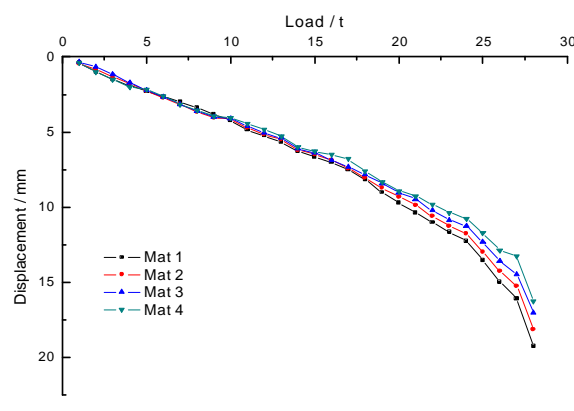

$\mathbf{b}$

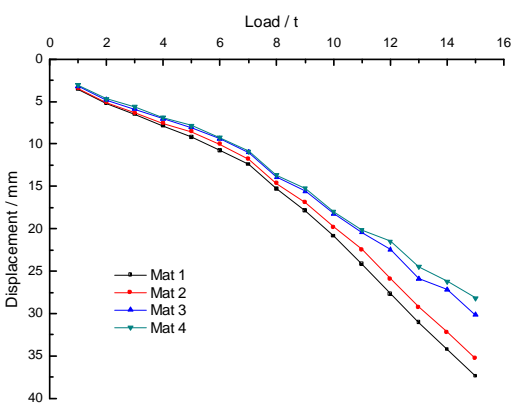

c

Fig.2 Load-displacement curve with different mat tested over

(a) test section A, (b) test section B and (c) test section C.

From Fig.2, the trend of all load-displacement curves over different soil is similar for each mat with different thickness. And the displacement is a little higher when mat 1 is tested over all soil 
conditions compared with other mats tested. The displacement is $4.62 \mathrm{~mm}$ when mat 1 is tested over Middle-strength soils with load applied to $10 \mathrm{t}$, while $4.38 \mathrm{~mm}$ for mat 4 . Increasing the mat thickness would improve the mat's bearing ability tinily. For example, thickness is approximately $10 \mathrm{~mm}$ more for mat 4 than mat 1, while displacement only decreases 5.1\% and weight increases $20 \%$ sharply under mats tested over Medium-strength soils. In addition, the displacement for mat 1 decrease 3.6\% compared with mat 4 when mats are tested over High-strength, while displacement decreases 14.2\% when mats are tested over Low-strength soils. It can be concluded that the lower soil foundation strength is, the more apparently that increasing the mat thickness improves bearing ability.

\section{Soil condition}

Soil condition plays an important role in mats' bearing ability [7]. For mat 1, the differences in soil condition are observed to cause differences in mat displacement and strain with load applied. The maximum displacements over different soil condition are selected for a comparative analysis (as is shown in Fig.3). From Fig.3, for 10t applied load, displacement is $0.38 \mathrm{~mm}$ lower when matting systems are installed over Middle-strength soil foundation compared with over High-strength soil foundation with load placed in load Location 1, whereas displacement is approximately four times greater for the Low-strength soil foundation results than for the Middle-strength soil foundation results. This is reasonable because the stress from the applied loading must be either supported by the soil foundation or dissipated through deformation of the soil foundation. Higher-strength soils can support more applied stress than lower-strength soils with less deformation [1]. The displacements for Load case 2 are also shown in Fig.3. When load is applied to 10t, the maximum mat displacements are $6.36 \mathrm{~mm}, 5.03 \mathrm{~mm}$ and $21.93 \mathrm{~mm}$ with matting systems installed over test section $\mathrm{A}, \mathrm{B}$ and $\mathrm{C}$ respectively. Fig. 4 shows the load-strain curve of static load test. It can be seen that the relationship between strain and soil foundation is similar to the relationship between displacement and soil foundation which Fig.4 reveals.

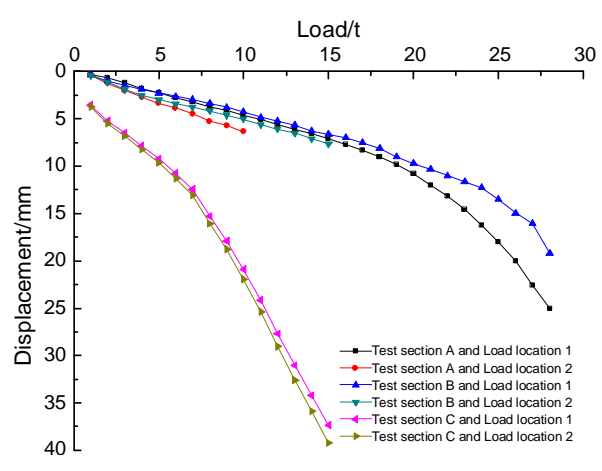

Fig.3 Load-displacement curve with mat 1tested over different test section

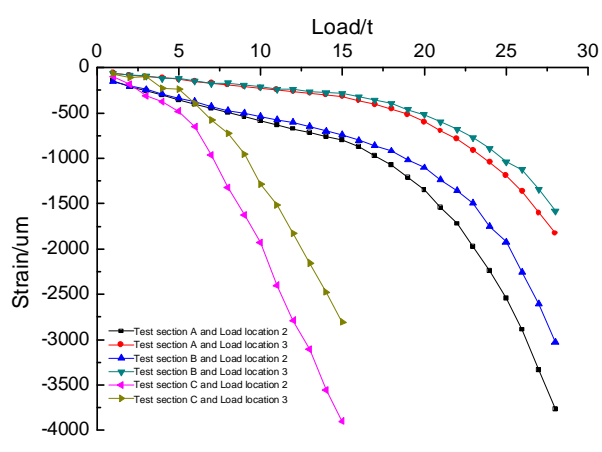

Fig.4 Load-strain curve with mat 1tested over different test section

In general, the results of soil condition effect on instrumentation readings obtained in this study are in agreement with previous studies, in which the mats' displacement and strain are affected by the strength of soil foundation tremendously [7]. It is worth to note that the strength of soil condition affects results more and more apparently, as the mount of applied load increases. On the other hand, for design aircraft, Middle-strength soil foundation causes only little higher displacement and strain than High-strength soil foundation, but much lower than Low-strength soil foundation. A study by [8] reports that the displacement decreases quadratically with the increase of strength of soil foundation. So, for a design aircraft, the required strength of soil foundation (actually base thickness) may be decided to prevent some displacement and strain limitation. Combined with the test results, it can be concluded that it may be not appropriate to decrease displacement and strain by increasing the base thickness when base has reached required strength.

Before tests, previous empirical design method is used to calculate the required base thickness based on the original design equation for flexible pavement [9]. The $\mathrm{S}$ aircraft is designed to operate 
1000 passes on a matting system surface and the required minimum thickness is calculated by subtracting equivalent thickness of the mat from the standard flexible pavement thickness calculated by the equation. However, the equivalency curve for different mats is not known because of mats' special sandwich structure and lacking large full-scale tests. So, considering many factor such as calculated thickness by design equation, austere airfield construction timeline, construction technique and so on, two types soil foundations (test section A and test section B) are suggested to be used as mats' pavement. For the mat and design aircraft mentioned in this study, test section A can fully meet the demand requirement of mats' using in the austere airfield construction, providing more strength than test section $\mathrm{C}$ and spending less construction time than test section $\mathrm{B}$. If matting systems are designed for a heavier weight and higher tire pressure aircraft, test section A may be replaced by test section B.

Lock

Load is transferred to adjacent mats by locks, reducing the stress and displacement of mat or soil foundation. The differences in load location are observed to research how locks effect the mats' displacement and strain. Fig.5 shows the curve of the maximum displacement with different load location when mats are installed over Middle-strength soil foundation. From Fig.5, Load location 4 causes the highest displacement, because the mat corner is least affected by locks. It is concluded that when load applied on the mat corner which has not any restraint, the bent deformation appears, making the mat damaged easily. For load location 4, the displacement is $8.45 \mathrm{~mm}$ when load applied to $10 \mathrm{t}$. However, the displacements for load location 1,2 and 3 are $4.62 \mathrm{~mm}, 6.36 \mathrm{~mm}$ and $2.24 \mathrm{~mm}$, respectively. Different load location causes a decrease of $45.3 \%, 24.7 \%$ and $73.5 \%$ in displacement respectively compared with load location 4 . The load locations where the mat gets the worst failure are in the order of mat corner, the longitudinal side, the middle point of mat, and the transverse side.

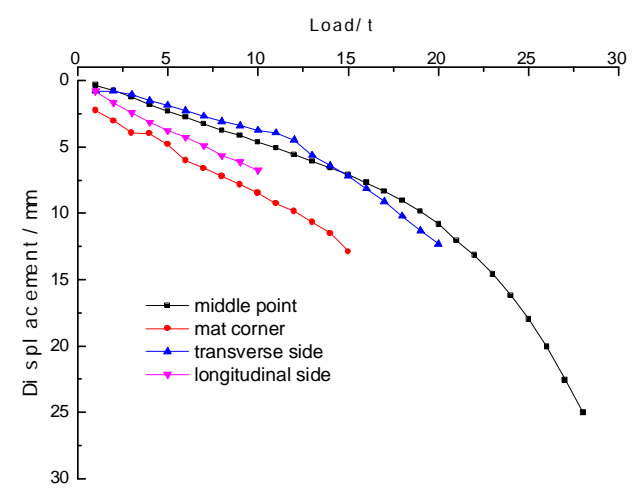

Fig.5 Load-displacement curve with different loading location

The displacement of each deflection sensors point when load applied on the transverse side (load location 3) is shown in Fig.6. When load is applied in the initial stage, some locks have the supported force. For example, the point 4 in the adjacent slab has apparent displacement, but the main supported object is only mat itself loaded by force. As applied load increases, the clearance between locking cam and keyhole becomes gradually smaller and the capacity of lock transferring energy increases rapidly. When applied load reaches to $10 \mathrm{t}$, the displacement of point 10 is $1.34 \mathrm{~mm}$, about $35.7 \%$ of maximum value $3.75 \mathrm{~mm}$, and when applied load reaches to $20 \mathrm{t}$, the displacement of point 10 is $5.41 \mathrm{~mm}$, about $43.9 \%$ of maximum value $12.32 \mathrm{~mm}$. The load is transferred to other adjacent mats by locks apparently. The phenomena that the point 5 and point 14 present opposite displacements can be explained in that load urges locks of nine mats to adjust to the new environment.

Fig.7 illustrates load-strain curve of strain gauges points on the mats surface with load applied on the transverse side (load location 3). As can be seen in Fig.7, when load is applied in the initial stage, the variety of strain is large and the change is in an irregular way due to locks' adjustment and error. As applied load increases, all mats go steady gradually and locks transfer load through corresponding coefficients. The coefficients of strain around locks are calculated by a linearity regression method. 
When load applied from $10 \mathrm{t}$ to $20 \mathrm{t}$, the transferring coefficient of lock around point 16 is between 0.65 and 0.90 , point 11 between 0.78 and 1.0 and point 3 between 0.48 and 0.58 . Therefore, the lock's load transferring capacity is not only influenced by the structure itself, but also by the load position, applied load value and locks' position.

Based on the phenomenon in the test about locks, further improvement into the locks design should be recommended. In mats' corner, a new style connection can be set to connect the adjacent mats to decrease displacement, such as panels interlock with overlapping and interlocking edge connections. In order to open the locks easily after aircrafts traffic the matting system, the clearance between locking cam and keyhole is designed large and conservative. So it is feasible to urge the locks transfer load earlier by decreasing the clearance between locking cam and keyhole. In addition, it is also feasible to decrease the longitudinal side dimension properly.

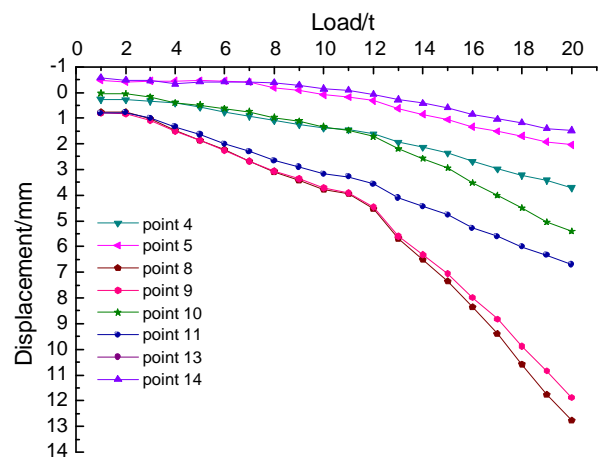

Fig.6 Load-displacement curve with load placed on load location 3

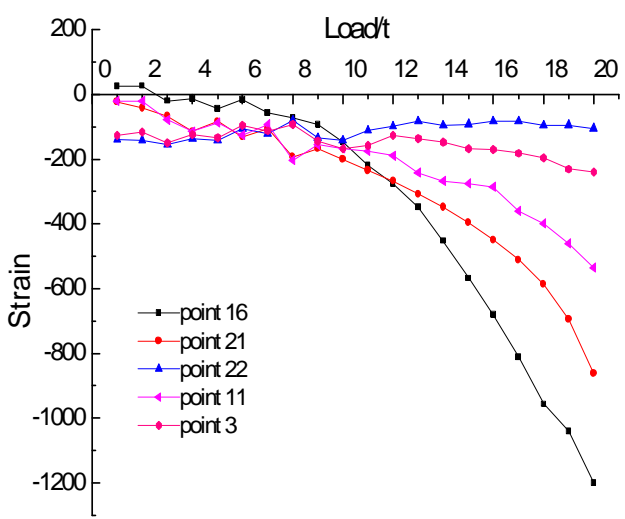

Fig.7 Load-strain curve with load placed on load location 3

Interlocking action

Like prefabricated concrete blocks, the matting system of aluminum honeycomb when load applied also produces interlocking action. Interlocking action is a phenomenon that the force in horizontal direction is presented when mat is loaded by the force in vertical direction, and transferred to adjacent mats through joints [10]. Although there is a small clearance left when mats are designed and produced, and the mats are only connected by locks, mats may gradually contact with each other and transfer load when mats are used. In order to evaluate interlocking action on matting system, an appropriate amount of small sand is filled in joints between mats and then load is applied to mats. Fig. 8 illustrates load-displacement curve with sand filled in joints. From Fig.8, it is concluded that interlocking action can obviously reduce displacement. When applied load reaches to 10t, the displacements with different loading positions (Load location 1, Load location 2, Load location 3, Load location 4) are reduced to $0 \mathrm{~mm}, 0.29 \mathrm{~mm}, 1.7 \mathrm{~mm}, 3.1 \mathrm{~mm}$ respectively. Interlocking action produces a beneficial effect on improving bearing capacity when load applied on the mat corner.

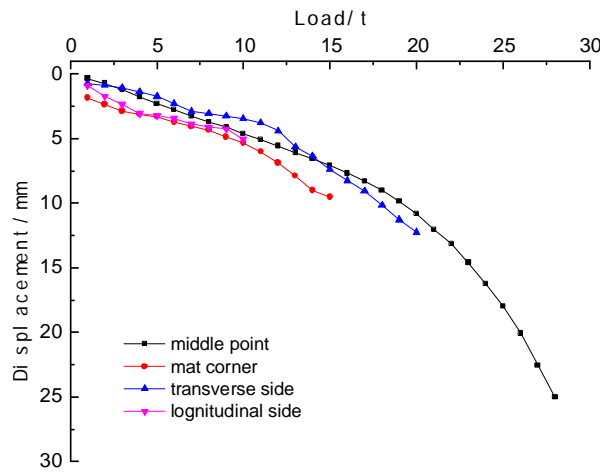

Fig.8 Load-displacement curve with sand filled in joints 
Although the load is mainly transferred by locks, the joints also transfer local load sometimes. As is discussed in previous section, conservative joints are designed considering the mats' remove and replacement. So, it is feasible to reduce the joints' width properly when mats are installed over the pavement. However, the values of proper joints' width should be decided by other tests.

\section{Void}

Three voids cases are investigated to research the void effect on bearing capacity of aluminum honeycomb mat. Three holes with $800 \mathrm{~mm}, 500 \mathrm{~mm}$ and $400 \mathrm{~mm}$ in diameter, and $32 \mathrm{~mm}, 17 \mathrm{~mm}$ and $12 \mathrm{~mm}$ in depth are excavated by twist drill on soil foundation. In order to make a comparative analysis between the most adverse conditions of the foundation disengagement and the static loading test, the test of the foundation disengagement adopts the mode of applying a continual loading to the mat at the location of disengagement rather than the simulated passage of the loader across the mat. Fig.9 illustrates the load-displacement curve with disengaging on bearing capacity of mat.

From Fig.9, it can be seen that the bigger voids are, the more the displacement is. When applied load reaches to $10 \mathrm{t}$, the displacements are $26.0 \mathrm{~mm}, 12.6 \mathrm{~mm}$, and $9.4 \mathrm{~mm}$ respectively. If disengagement on bearing capacity of mat is apparent, the mat takes the form of plastic deformation immediately when load applied. Void case 3 cause the minimum displacement without exceeding allowable deflection. Fig.10 illustrates the fitting curve of deflection basin with void case 1 under the mat. As can be seen in Fig.10, the deflection basin curve is approximately a concave curve. As the distance to load location increases, the displacement decreases gradually, as well as the rate of displacement decreasing. As the applied load increases, the value of the maximum displacement increases, as well as the diameter of deflection basin and the slope of deflection basin curve.

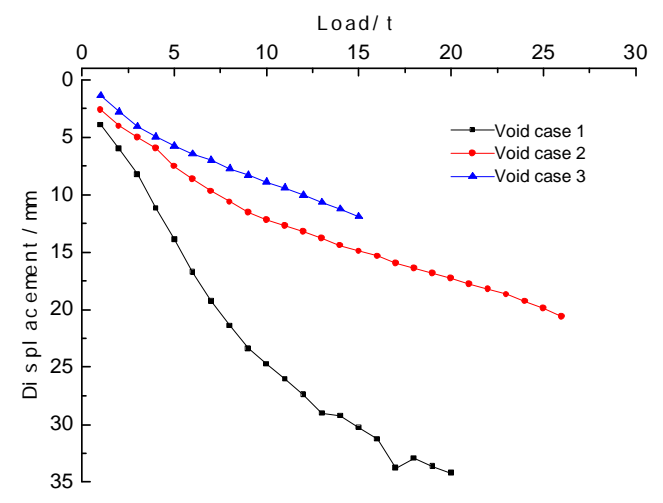

Fig.9 Load-displacement curve of test with voids under mats

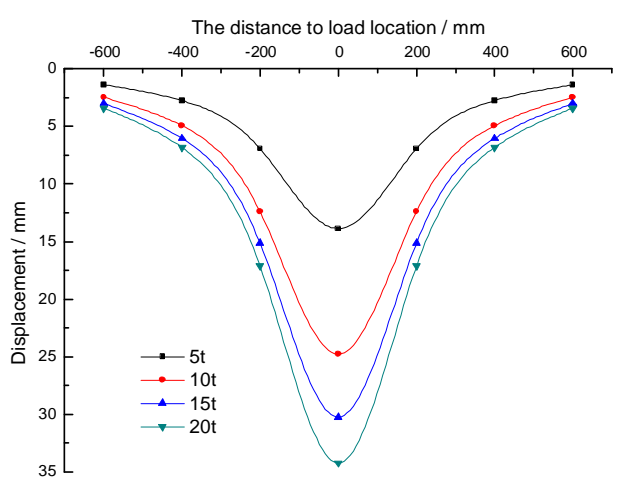

Fig.10 Deflection basin curve

\section{Conclusions}

Prototype aluminum honeycomb mats are designed for $\mathrm{S}$ aircraft and tested in the field experiment. Mats' performances (mainly displacement) under simulated aircraft traffic are observed. Different factors that affect mats' bearing ability are evaluated. The following conclusions are reached from the results of the testing:

(1) Prototype mats perform well under S aircraft load, except mats installed over Low-strength soil foundation or voids. The maximum displacement is $8.45 \mathrm{~mm}$ with load applied on mats' corner and is lower than allowable displacement. It is feasibility of aluminum honeycomb mat to sustain $\mathrm{S}$ aircraft over austere airfield pavement.

(2) It is not cost-efficient that increasing the mat thickness improves mats' bearing ability. Matting system 1 is selected for full-scale testing.

(3) For the mat and design aircraft mentioned in this study, test section A (Middle-strength soil) can fully meet the demand requirement of mats' using in the austere airfield construction. If matting 
systems are designed for a heavier weight and higher tire pressure aircraft, test section A (Middle-strength soil) may be replaced by test section B (High-strength soil).

(4) The worst positions in which the mat is loaded are in the order of mat corner, the longitudinal side, the middle point of mat and the transverse side. The locks can increase the integrity of matting system, enhancing its bearing capacity. However, the locks' transferring capacity is affected by such factors as load position, load value and so on. Interlocking action can increase mats' bearing capacity when loaded on the mat corner. Further optimisation of the panel, lock and joint design can improve upon the mats' performance presented in this paper. In addition, joints widths are required to validate that locks and interlocking action can transfer the load at the best, increasing load-transfer efficiency.

(5) The bigger voids are, the more apparently voids affect mats' bearing ability. For aluminum honeycomb mat under S aircraft load, void case $3(400 \mathrm{~mm}$ in diameter, $12 \mathrm{~mm}$ in depth) is the allowable limitation.

\section{Recommendations}

Further research into the aluminum honeycomb matting system design is recommended to reduce costs, improve performance and reduce installation timing. Further investigation into the load transfer mechanisms and load transfer characteristics of the locks and joints is recommended. In addition, the effect of honeycomb defects and soil foundation evenness requires further investigation.

\section{References}

[1] Doyle, J. D, Howard, I. L, Gartrell, C. A, Anderton, G. L, Newman, J. K and Berney, E. S. Full-Scale instrumented testing and three-dimensional modeling of airfield matting systems. International Journal of Geomechanics, 14(2014)161-170.

[2] White, T.D. Theoretical landing mat analysis miscellaneous. Vicksburg, MS: US USACE, USACE / S-71-21. 1971

[3] Gartrell, C. A, Newman, J. K, Anderton. Performance measurements of pavement matting systems by full-scale testing over differing soil strengths. Journal of Materials in Civil Engineering, 21(2009)561-568

[4] Unified Facilities Criteria (UFC). Beijing: Field Test Methods of Subgrade and Pavement for High Engineering, UFC JTG E60. 2008.(in chinese)

[5] Z Liu. Compression properties of honeycomb sandwich plates with different shape delamination disfigurements. Acta Material Composite Siniea. 25(2009)153-158. (in chinese)

[6] S PAN. End compression failure of honeycomb sandwich panels containing Interfacial. Acta Material Composite Siniea.24(2007)121-127. (in chinese)

[7] Guopin CEN, Chuanlong CHENG. Experimental study on the bearing capacity of the aluminum honeycomb sandwich panel. Journal of air force engineering university (Natural science edition), 15 (2014)1-4. (in chinese)

[8] Xianming Zhang. Influencing depth under aircraft loads of runway. Journal of Beijing University of Aeronautics and Astronautics. 40(2014)427-432. (in chinese)

[9] ,Xingzhong WENG. "Research on structure design criteria of asphalt concrete pavement for military airport. "Journal of air force engineering university (Natural science edition), 6(2005) pp. 8-10

[10] Huoming WANG. Experimental Research on Bearing Capacity Characteristics of Pavement of Prefabricated Concrete Blocks. Technology of Highway and Transport, Vol(2012) pp. 24-30. (in chinese) 